\title{
Coronary Artery Anomalies by Multidetector Computed Tomography
}

\author{
Lina Hablas ${ }^{1,}$, , Hanan Elahwal ${ }^{1}$, Taymour Mostafa $^{2}$, Rasha Elshafey ${ }^{1}$, Mohamed Elashwah ${ }^{1}$ \\ ${ }^{1}$ Department of Radiodiagnosis and Medical Imaging, Faculty of Medicine, Tanta University, Tanta, Egypt \\ ${ }^{2}$ Department of Cardiology, Faculty of Medicine, Tanta University, Tanta, Egypt
}

\section{Email address:}

linahablas@gmail.com (L. Hablas), drhananmohamed1956@gmail.com (H. Elahwal), timo_medy@yahoo.com (T. Mostafa), drrashaelshafey@yahoo.co.uk (R. Elshafey),mohamed86_9@hotmail.com (M. Elashwah)

${ }^{*}$ Corresponding author

\section{To cite this article:}

Lina Hablas, Hanan Elahwal, Taymour Mostafa, Rasha Elshafey, Mohamed Elashwah. Coronary Artery Anomalies By Multidetector Computed Tomography. International Journal of Medical Imaging. Vol. 7, No. 2, 2019, pp. 29-39. doi: 10.11648/j.ijmi.20190702.11

Received: May 13, 2019; Accepted: June 12, 2019; Published: June 26, 2019

\begin{abstract}
The prevalence of coronary artery anomalies (CAAs) is reported to be $0.3 \%$ to $2 \%$ of the general population. Asymptomatic CAAs are more common and have a better prognosis. Nevertheless, some of these anomalies are linked with symptoms such as syncope, chest pain, and sudden cardiac death. The aim of the study was to determine the prevalence and describe the coronary congenital anomalies and their variations using coronary CT angiography. MD (320) CT angiography was used to prospectively examine 630 patients with either myocardial ischemic symptoms or suspected coronary anomalies by echocardiography or invasive coronary angiography. Contrast injection with ultra-thin cardiac scanning were then carried out. Images were analyzed with multiplanar reformations (MPR), curved multiplanar reformations (cMPR), maximum intensity projections (MIP) \& volume rendering techniques (VR). Coronary artery anomalies were found in 217/630 patients (34.44\% incidence), $69(10.95 \%)$ anomalies were of vessel origin with good agreement between CTA and ICA results (K= $0.630), 140(22.22 \%)$ were of vessel course and intrinsic vessel anomalies with moderate agreement between CTA and ICA results $(\mathrm{K}=0.448)$, and $8(1.27 \%)$ were of vessel termination with very good agreement between CTA and ICA results $(\mathrm{K}=$ 1.000). from this study we conclude that the prevalence of coronary anomalies is substantially higher with coronary CTA than with invasive coronary angiography and ECG gated multidetector coronary CT angiography allows accurate anatomical assessment of coronary artery anomalies.
\end{abstract}

Keywords: Coronary Artery Anomalies, CTA, Prevalence of Coronary Anomalies

\section{Introduction}

Asymptomatic coronary artery anomalies are more common and have a better prognosis. Nevertheless, some of these anomalies are linked with symptoms such as syncope, chest pain, and sudden cardiac death. About $20 \%$ of coronary artery anomalies produce life threatening symptoms including arrhythmias, syncope, myocardial infarction, or sudden death while $80 \%$ are benign $[1,2]$.

The most cited study describing the various coronary variants and anomalies based on catheter angiography by Angelini et al. who described and classified various anomalies based on origin, course, branching pattern, and termination of coronary arteries [3].
Conventional coronary artery angiography is not the ideal modality to define the course of these vessels. It has been a constant endeavor in coronary artery imaging to find a variety of non-invasive techniques that may successfully replace invasive conventional coronary angiography. Some of these techniques like computed tomography (CT) and magnetic resonance have shown promising results $[4,5]$.

Multi-detector coronary CT angiography allows performing a flexible post-processing as curved multiplanar reformations (c-MPR), maximum intensity projections (MIP) and $3 \mathrm{D}$ volume rendering techniques. Recent studies have demonstrated a better diagnostic value of CTCA in diagnosing coronary artery anomalies when compared to invasive coronary angiography. On the other hand, conventional coronary angiography allows both diagnostic 
and therapeutic interventions and provides a better visualization of lesions in distal coronary branches and assessment of high-grade calcific stenoses where CTCA ability of quantifying the grade of luminal obstruction is limited [6].

The aim of the study was to determine the prevalence and describe the coronary congenital anomalies and their variations using coronary CT angiography.

\section{Patients and Methods}

A prospective study including all patients who were scheduled for elective multislice CT coronary angiography of coronary arteries between January 2017 and January 2019. All patients were scanned with 320-row multidetector CT scanner (Aquilion One, Toshiba Medical Systems, Otawara, Japan). The study included 630 patients (280 males and 350 females) with their age ranged from 3 days to 81 years.

Written informed consent was obtained from all patients (or their parents) participated in this study after full explanation of the benefits and risks of the procedure.

Inclusion criteria included patient who had symptoms suggestive of ischemic heart disease and patient who had suspected coronary artery anomaly by echocardiography and/or by invasive coronary angiography. Exclusion criteria included patient who was clinically unstable to withstand the duration of CT examination, patient with history of allergy to IV contrast media that will be used, patient who had impaired renal function (Creatinine level $\geq 1.5 \mathrm{mg} / \mathrm{dl}$ ), patient who could not tolerate the required breath holding time for examination, pregnant women and patients with bad general condition and needing life support.

All patients were subjected to proper history taking as diabetes mellitus or hypertension, previous investigations and clinical examination. Patients were asked to be fasting 4-6 hours before scan, avoid caffeine and smoking on the day of CT examination. IV cannula was inserted after heart rate control in the patient preparation room. The right antecubital vein was used for all adult patients to ensure high injection flow rate and shorter route for contrast bolus to reach the heart. For pediatric patients, a suitable intravenous cannula (20-to 24-gauge) was placed in the right upper limb vein (in 58 cases), or in a lower limb peripheral vein (in 76 cases). Patients were given gown to put on and then instructed to lie supine on the scanner table with arms raised above their heads. ECG electrodes were applied to the chest wall. The IV line was connected and test injection with saline was done to ensure a good IV access with no extravasation. Breath holding instructions were given to the patients to avoid respiratory motion artifacts. Finally, $5.0 \mathrm{mg}$ sublingual Isosorbid Dinitrate was given unless there was contraindication to its use (low blood pressure, below $100 / 70$; in 31 patients). 50 to $100 \mathrm{~mL}$ of non ionic, non diluted IV contrast media was administered for adult patients (Ultravist $370 \mathrm{mgI} / \mathrm{ml}$ ) at a flow rate of $3.5-6.5 \mathrm{ml} / \mathrm{sec}$ through the peripherally inserted IV cannula using dual-head powered automatic injector (Stellant D, Medrad, Indianola,
PA, USA) followed by IV saline flush injection of same flow rate to improve the contrast opacification and homogeneity. In pediatric patients: contrast media (Ultravist $300 \mathrm{mgI} / \mathrm{ml}$ ) was injected at a flow rate of $0.8-2.5 \mathrm{ml} / \mathrm{sec}$. Images were reconstructed at $0.5 \mathrm{~mm}$ slice thickness and $0.5 \mathrm{~mm}$ interval with smooth and sharp reconstruction kernels (FC03 \& FC05 respectively) at $75 \%$ of R-R interval and at the best systolic and diastolic phases. The reconstructed images were transferred to a workstation (Vitrea Fx, Vital Images, USA) to obtain axial, sagittal and coronal reformatted images. Also maximum intensity projection, $3 \mathrm{D}$ volume rendered images, and curved planar reformations. Evaluation of coronary arteries through their analysis on the basis of the coronary dominance (right, left, co-dominant), vessels origin (single coronary artery, anomalous origin from contra lateral sinus or non coronary sinus, anomalous origin with coronary ostium within the aortic root or near the actual aortic sinus of Valsalva), origin outside the aorta (from pulmonary artery)), course, termination, caliber, number, intrinsic coronary anomalies (myocardial bridging, ectasia, aneurysm) \& contrast opacification.

Statistical analysis of the data: Data were fed to the computer and analyzed using IBM SPSS software package version 20.0. (Armonk, NY: IBM Corp). Qualitative data were described using number and percent. Significance of the obtained results was judged at the $5 \%$ level. The used tests were Kappa ( $\kappa)$ tests for agreement with strength of agreement as follows: poor (value of $K<0.20$ ), fair (value of $K=0.21$ 0.40 ), moderate (value of $\mathrm{K}=0.41-0.60)$, good (value of $\mathrm{K}=$ $0.61-0.80$ ) and very good (value of $\mathrm{K}=0.81-1.00$ ).

\section{Results}

Age of patients ranged from 3 days to 81 years old with the most common age group was 50 - 60 years old including 187 patients. They were 280 males and 350 females. The most common complaint of the patients was atypical chest pain in 368 patients, while the least common complaint was fainting attacks in 3 patients.

From 496 adults patients, 390 (78.6\%) patients had right dominant circulation, while $52(10.5 \%)$ patients had left dominant circulation, and $54(10.9 \%)$ patients had codominant circulation. Meanwhile it was difficult to assess dominance in studied pediatric patients. Left main coronary artery bifurcated into left anterior descending artery and left circumflex artery in $417(84.1 \%)$ patients, while in 79 $(15.9 \%)$ it trifurcates into LAD, LCx and ramus intermedius.

From the 630 patients included in the study, 217 anomalies were detected with prevalence of $(34.44 \%), 69(10.95 \%)$ anomalies were of vessel origin, $140(22.22 \%)$ anomalies were of vessel course and intrinsic vessel anomalies and 8 $(1.27 \%)$ anomalies were of vessel termination. Regarding to anomalous origin, 37 anomalies were detected by both CT angiography (CTA) and invasive coronary angiography (ICA), 32 anomalies were detected by CTA only and 6 anomalies were detected by ICA only, these 6 anomalies were detected in pediatric patients with high heart rate that 
prohibited visualization of coronary arteries. This lead to good agreement $(\mathrm{K}$ value $=0.630)$. As regard anomalous course, 56 anomalies were detected by both CTA and ICA, 84 anomalies were detected by CTA and 15 anomalies were detected by ICA and missed by CTA leading to moderate agreement $(\mathrm{K}$ value $=0.448)$. As regard anomalous termination, all 8 anomalies were detected by both CTA and ICA leading to very good agreement $(\mathrm{K}$ value $=1.000)$.

Right coronary artery anomalies included $13(2.1 \%)$ patients with anomalies in origin and fair agreement $(\mathrm{K}=$ $0.391 ; \mathrm{P}<0.001), 14(2.2 \%)$ patients with anomalies in course and very good agreement $(\mathrm{K}=0.811 ; \mathrm{P}<0.001)$, and only one patient with anomaly in termination with right coronary artery fistulous connection to the right ventricle could be detected by both CTA and ICA. This gave very good agreement $(\mathrm{K}$ value $=1.000 ; \mathrm{P}$ value $<0.001)$. Distribution of number and percentage of anomalies in origin are mentioned in (table 1). From 14 cases with anomalies in course, 8 cases showed ectasia with very good agreement $(\mathrm{K}=1.000 ; \mathrm{P}<0.001), 3$ cases showed $\mathrm{RCA}$ bridging with moderate agreement $(\mathrm{K}=0.498 ; \mathrm{P}<0.001)$, one case with RCA kink and very good agreement $(\mathrm{K}=1.000, \mathrm{P}<0.001)$ and one case with RCA splitting and good agreement $(\mathrm{K}=0.666$; $\mathrm{P}<0.001)$.

From all studied (630) patients, 19 (3\%) patients had left main coronary artery (LMCA) anomalies. Eleven (1.8\%) patients had anomalies in its origin with moderate agreement $(\mathrm{K}=0.464 ; \mathrm{p}<0.001) \& 8(1.3 \%)$ patients had anomalies in its course with very good agreement $(\mathrm{K}=1.000$; $\mathrm{p}<0.001)$. Distribution of patients with left main coronary artery anomalies in origin is mentioned in table 2 .

Eight $(1.3 \%)$ patients showed anomalies in LMCA course, $6(75 \%)$ patients had short LMCA with very good agreement $(\mathrm{K}=1.000 ; \mathrm{p}<0.001)$. One $(12.5 \%)$ patient showed LMCA aneurysm and one (12.5\%) patient had LMCA ectasia with very good agreement $(K=1.000 ; p<0.001)$. Distribution of left anterior descending artery anomalies is mentioned in table 3. Anomalies in LAD origin include 7 cases with absent LM coronary artery and separate ostia of both LAD and LCx with moderate agreement $(\mathrm{K}=0.598 ; \mathrm{P}<0.001)$ and 6 cases with anomalous origin from right coronary sinus either with prepulmonic course (in 5 cases) or trans-septal course (in 1 case) and very good agreement $(\mathrm{K}=1.000 ; \mathrm{P}<0.001)$. From 106 patients with anomalies in LAD course, 9 patients showed LAD ectasia with good agreement $(\mathrm{K}=0.798$; $\mathrm{P}$ $<0.001$ ), 90 patients with myocardial bridging and fair agreement $(\mathrm{K}=0.267 ; \mathrm{P}<0.001)$ and 7 cases with duplicated LAD and good agreement $(\mathrm{K}=0.733 ; \mathrm{P}<0.001)$. One case with left anterior descending coronary artery anomaly in termination and fistulous connection to right ventricle with very good agreement $(K=1.000 ; p<0.001)$.

Distribution of Left circumflex artery (LCx) anomalies are mentioned in table 4. Variable anomalies in $\mathrm{LCx}$ origin included 7 patients with absent LM coronary artery and separate ostia of both LAD and LCx, 2 patients with anomalous origin of $\mathrm{LCx}$ from right coronary sinus by separate ostia and retro-aortic course, 1 patient with anomalous origin of LCx from non coronary sinus and another case with anomalous origin of LCx from 1st diagonal branch. Four $(0.64 \%)$ patients with anomalies in LCx course, They had ectasia with very good agreement $(\mathrm{K}=0.856$; $\mathrm{p}<0.001)$. Four patients showed left circumflex artery anomalies in termination, one with fistula to great cardiac vein, another one with fistula to right ventricle, other with fistula to right atrium and the last one with fistula of atrial branch of $\mathrm{LCx}$ to right atrium. They showed very good agreement $(\mathrm{K}=1.000 ; \mathrm{p}<0.001)$.

Table 1. Distribution of patients with right coronary artery anomalies in origin.

\begin{tabular}{|c|c|c|c|c|c|}
\hline & & & Number of patients & Percentage (\%) & Agreement (kappa test) \\
\hline \multirow{3}{*}{$\begin{array}{l}\text { From left } \\
\text { coronary sinus }\end{array}$} & \multicolumn{2}{|c|}{ By separate ostium with malignant interarterial course } & 5 & 38.5 & $\begin{array}{l}\mathrm{K}=0.246(\mathrm{P}<0.001) \\
\text { Fair agreement }\end{array}$ \\
\hline & \multirow{2}{*}{$\begin{array}{l}\text { By common ostium } \\
\text { with LMCA (single } \\
\text { coronary artery) }\end{array}$} & With prepulmonic course & 1 & 7.7 & $\begin{array}{l}\mathrm{K}=0.666(\mathrm{P}<0.001) \\
\text { Good agreement }\end{array}$ \\
\hline & & With retro-aortic course & 1 & 7.7 & $\begin{array}{l}\mathrm{K}=1.000(\mathrm{P}<0.001) \\
\text { Very good agreement }\end{array}$ \\
\hline \multirow{2}{*}{$\begin{array}{l}\text { From non } \\
\text { coronary sinus }\end{array}$} & \multirow{2}{*}{\multicolumn{2}{|c|}{$\begin{array}{l}\text { With normal origin of LMCA } \\
\text { By common ostium with LMCA (Single coronary } \\
\text { artery) }\end{array}$}} & 2 & 15.4 & - \\
\hline & & & 2 & 15.4 & $\begin{array}{l}\mathrm{K}=0.666(\mathrm{P}<0.001) \\
\text { good agreement }\end{array}$ \\
\hline High take off & \multicolumn{2}{|c|}{$\begin{array}{l}\text { Just above normal sinus } \\
\text { With malignant interarterial course }\end{array}$} & $\begin{array}{l}1 \\
1\end{array}$ & $\begin{array}{l}7.7 \\
7.7\end{array}$ & gore og \\
\hline \multicolumn{3}{|c|}{ Total number of patients } & 13 & 100 & $\begin{array}{l}\mathrm{K}=0.391(\mathrm{P}<0.001) \\
\text { Fair agreement }\end{array}$ \\
\hline
\end{tabular}

LMCA: left main coronary artery.

Table 2. Distribution of patients with left main coronary artery anomalies in origin.

\begin{tabular}{|c|c|c|c|c|c|}
\hline Anomaly & & & Number of patients & Percentage (\%) & Agreement (kappa test) \\
\hline \multirow{5}{*}{$\begin{array}{l}\text { From right } \\
\text { coronary sinus }\end{array}$} & \multirow{2}{*}{ By separate ostium } & with retroaortic course & 1 & 9.1 & \multirow{5}{*}{$\begin{array}{l}- \\
- \\
\mathrm{K}=1.000(\mathrm{P}<0.001) \\
\text { Very good agreement } \\
\mathrm{K}=-0.002(\mathrm{P}=0.955) \\
\text { poor agreement }\end{array}$} \\
\hline & & With prepulmonic course & 2 & 18.2 & \\
\hline & \multirow{3}{*}{$\begin{array}{l}\text { By common ostium } \\
\text { with RCA (single } \\
\text { coronary artery) }\end{array}$} & With trans-sental course & 2 & 182 & \\
\hline & & & & & \\
\hline & & With prepulmonic course & 1 & 9.1 & \\
\hline
\end{tabular}




\begin{tabular}{lllll}
\hline Anomaly & & Number of patients & Percentage (\%) & Agreement (kappa test) \\
\hline $\begin{array}{llll}\text { From non } \\
\text { coronary sinus }\end{array}$ & $\begin{array}{l}\text { With normal origin of } \\
\text { RCA }\end{array}$ & 1 & 9.1 & - \\
$\begin{array}{l}\text { Byigh take off } \\
\text { (single coronary artery) }\end{array}$ & 2 & 18.2 & $\begin{array}{l}\mathrm{K}=0.666(\mathrm{P}<0.001) \\
\text { Good agreement }\end{array}$ \\
$\begin{array}{l}\text { Just above normal sinus } \\
\text { From pulmonary artery (ALCAPA) }\end{array}$ & 1 & 9.1 & - \\
\hline
\end{tabular}

Table 3. Left anterior descending coronary artery anomalies among the studied 630 patients.

\begin{tabular}{|c|c|c|c|}
\hline Anomaly & $\begin{array}{l}\text { Number of } \\
\text { patients }\end{array}$ & $\begin{array}{l}\text { Percentage } \\
(\%)\end{array}$ & $\begin{array}{l}\text { Agreement } \\
\text { (kappa test) }\end{array}$ \\
\hline Anomalous origin & 13 & 2.1 & $\begin{array}{l}\mathrm{K}=0.696(\mathrm{P}<0.001) \\
\text { Good agreement }\end{array}$ \\
\hline $\begin{array}{l}\text { Anomalous course } \\
\text { and intrinsic } \\
\text { anomalies }\end{array}$ & 106 & 16.8 & $\begin{array}{l}\mathrm{K}=0.331(\mathrm{P}<0.001) \\
\text { Fair agreement }\end{array}$ \\
\hline $\begin{array}{l}\text { Anomalies of } \\
\text { termination }\end{array}$ & 1 & 0.16 & $\begin{array}{l}\mathrm{K}=1.000(\mathrm{P}<0.001) \\
\text { Very good agreement }\end{array}$ \\
\hline
\end{tabular}

Table 4. Left circumflex ( $L C x$ ) artery anomalies among the studied 630 patients.

\begin{tabular}{|c|c|c|c|}
\hline Anomaly & $\begin{array}{l}\text { Number } \\
\text { of patients }\end{array}$ & $\begin{array}{l}\text { Percentag } \\
\text { e (\%) }\end{array}$ & $\begin{array}{l}\text { Agreement } \\
\text { (kappa test) }\end{array}$ \\
\hline Anomalies in origin & 11 & 1.75 & $\begin{array}{l}\mathrm{K}=0.583(\mathrm{P}<0.001) \\
\text { Moderate agreement }\end{array}$ \\
\hline $\begin{array}{l}\text { Anomalies in course } \\
\text { and intrinsic } \\
\text { anomalies }\end{array}$ & 4 & 0.64 & $\begin{array}{l}\mathrm{K}=0.856(\mathrm{P}<0.001) \\
\text { Very good agreement }\end{array}$ \\
\hline $\begin{array}{l}\text { Anomalies of } \\
\text { termination }\end{array}$ & 4 & 0.64 & $\begin{array}{l}\mathrm{K}=1.000(\mathrm{P}<0.001) \\
\text { Very good agreement }\end{array}$ \\
\hline
\end{tabular}

Acute marginal branches of right coronary artery showed 3 $(0.5 \%)$. One case with anomalous origin directly from aorta. One case with ectasia and one case show fistulous connection to 1 st diagonal branch which showed fistulous connection to left ventricle with good agreement $(K=0.799$; $p<0.001)$.

Posterior descending artery anomalies included: 21 cases with anomalous origin either early origin at angle of the heart (in 9 cases) or anomalous origin from acute marginal branch (in 12 cases). Two cases with anomalous course with double PDA (in two cases). Overall good agreement of PDA anomalies was noticed with $\mathrm{K}$ value $=0.801 ; \mathrm{P}<0.001$.

Postero-lateral branch is one of the terminal branches of RCA. Two cases $(0.32 \%)$ showed anomalies in course with posterolateral branch myocardial bridging and they were detected by both CTA and ICA while one more case was missed by CTA and diagnosed by ICA. This gave good agreement $(\mathrm{K}$ value $=0.799 ; \mathrm{P}$ value $<0.001)$. One case showed anomalies in termination with posterolateral fistula to right bronchial artery and another side fistulous connection to right pulmonary artery. It was detected by both CTA and ICA with very good agreement $(\mathrm{K}$ value $=1.000 ; \mathrm{P}$ value $<0.001)$.

Diagonal branches of LAD showed $3(0.48 \%)$ anomalies, two of them were intrinsic anomalies, one case with diagonal proximal segment ectasia, another case with the third diagonal branch showed a partially calcified aneurysm with very good agreement $(K=1.000 ; \mathrm{p}<0.001)$. Another one case with anomalous termination with fistulous connection of 1 st diagonal branch to left ventricle with and good agreement $(\mathrm{K}=1.000 ; \mathrm{p}<0.001)$.

Obtuse marginal branches of LCx showed two (0.3\%) cases with anomalies, one case with ectasia and it was detected by both CTA and ICA, and another case with myocardial bridging and was detected only by CTA, leading to a good agreement $(\mathrm{K}=0.666 ; \mathrm{p}<0.001)$

\section{Cases}

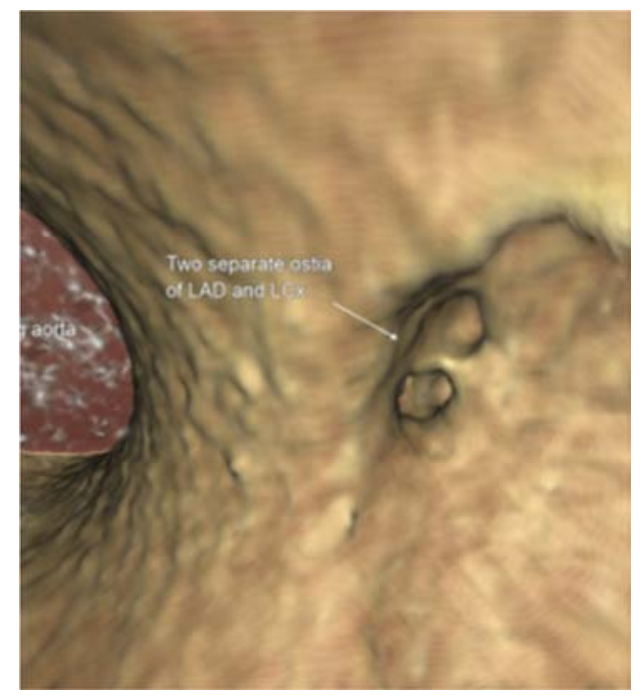

(A). 3D volume rendering image of coronary arteries

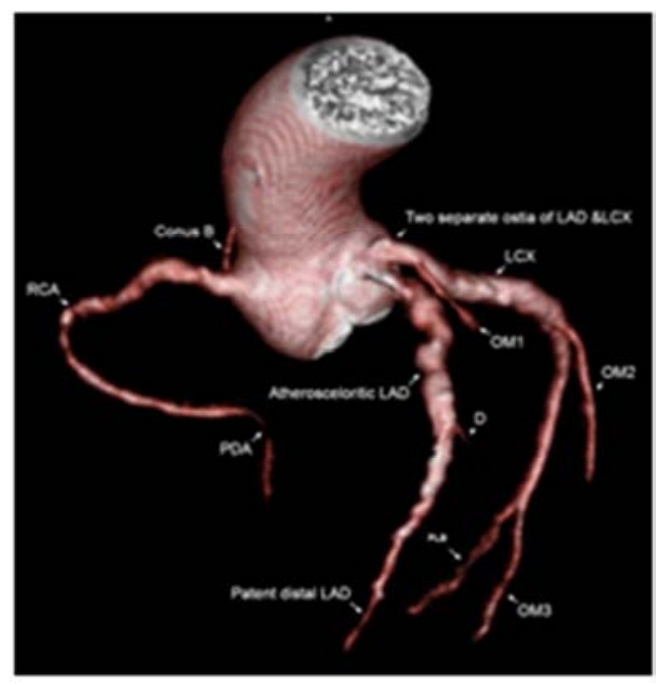

(B). Endoluminal view of left anterior descending artery (LAD) and left circumflex artery (LCx) ostia 


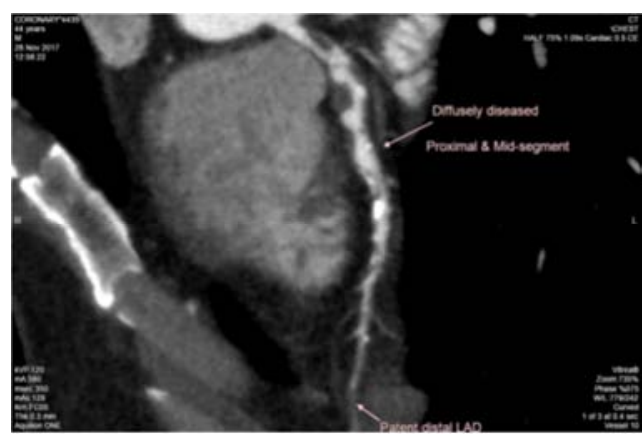

(C). Curved planar reformatted image of LAD

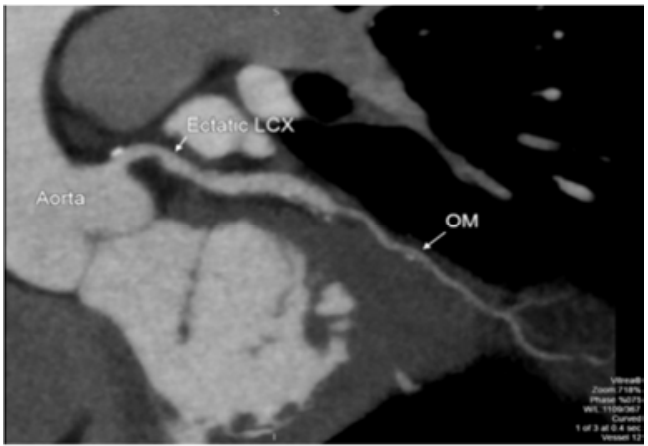

(D). Curved planar reformatted image of LCx

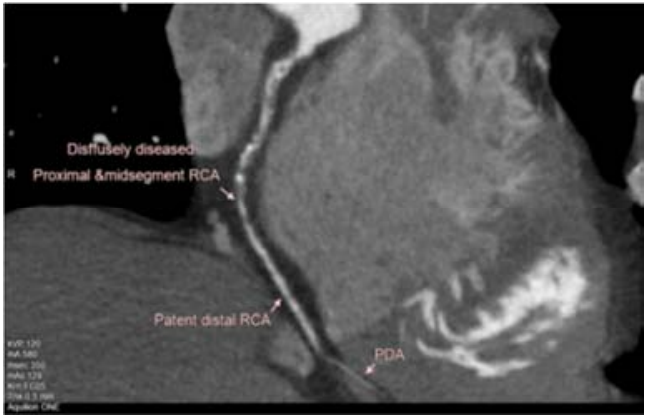

(E). Curved planar reformatted image of right coronary artery (RCA)

Figure 1. A 44-year-old male patient presented with non visualized LAD on previous PCI. MD-CTA reveals absence of LMCA with separate ostia of both $L A D$ and $L C x(A, B)$, co-dominant coronary circulation (A), dilatation of the proximal and mid segments of $L C x(D)$, subintimal calcified atherosclerotic plaques scattering in the scanned vessels with beaded outlines $(A, C, D$ and E) and total calcium score $=384$.

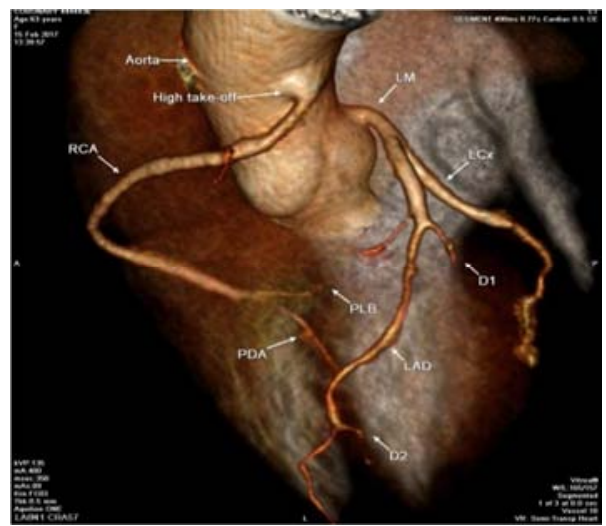

(A). 3D volume rendering image of heart and coronary arteries (Lateral oblique view)

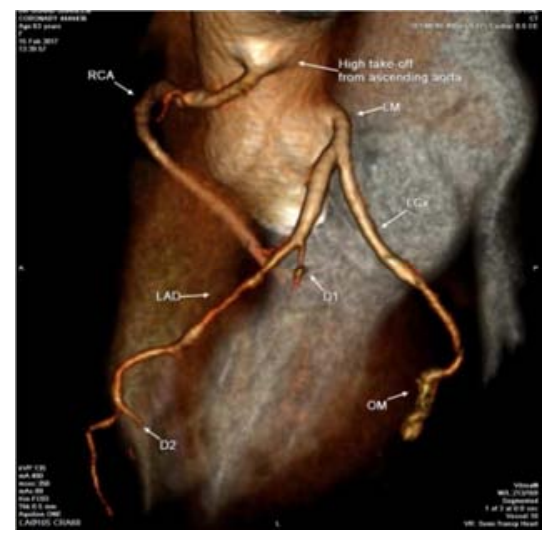

(B). 3D volume rendering image of heart and coronary arteries (Left lateral view)

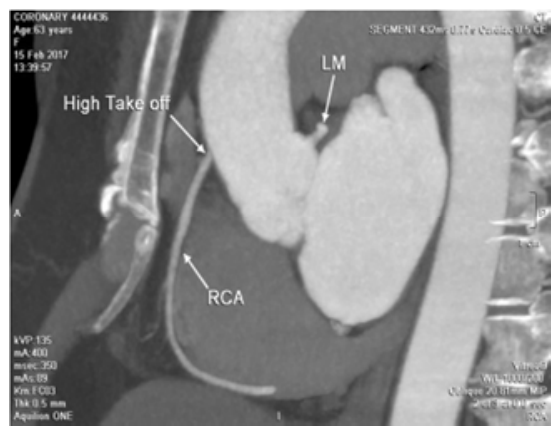

(C). Sagittal MIP image of RCA

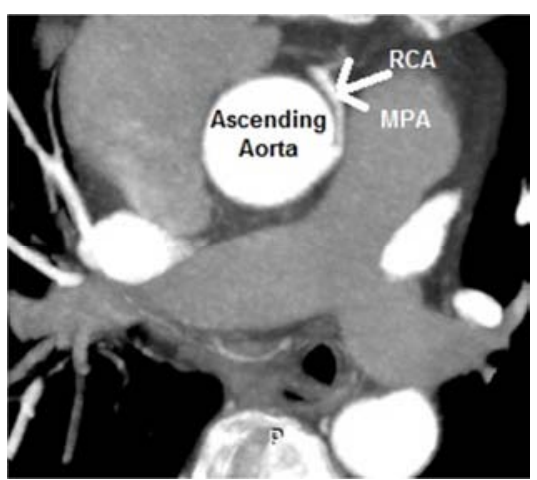

(D). Axial oblique MIP image of RCA

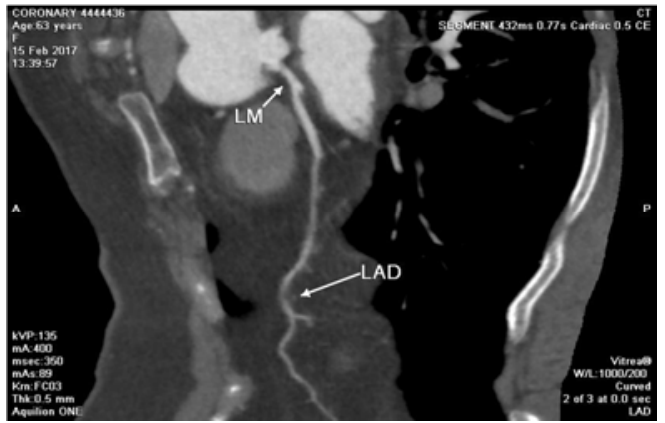

(E). Curved planar reformatted image of LAD

Figure 2. A 63 -year-old female patient with atypical chest pain. MDCTA reveals Right dominant coronary circulation (A), anomalies origin of RCA from anterior aorta with high take off and malignant inter-arterial course without luminal compression $(A-D), L A D$ supplies 2 patent diagonal branches $(A, B)$ and $L C x$ supplies a single $O M$ branch $(A, B)$ and no atherosclerotic changes with calcium score $=0$. 


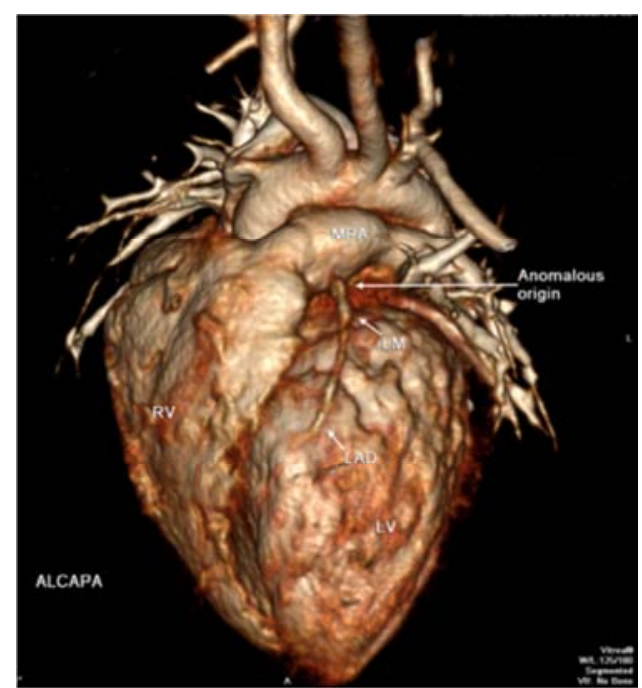

(A). 3D volume rendering image of heart and coronary arteries (Anterior view)

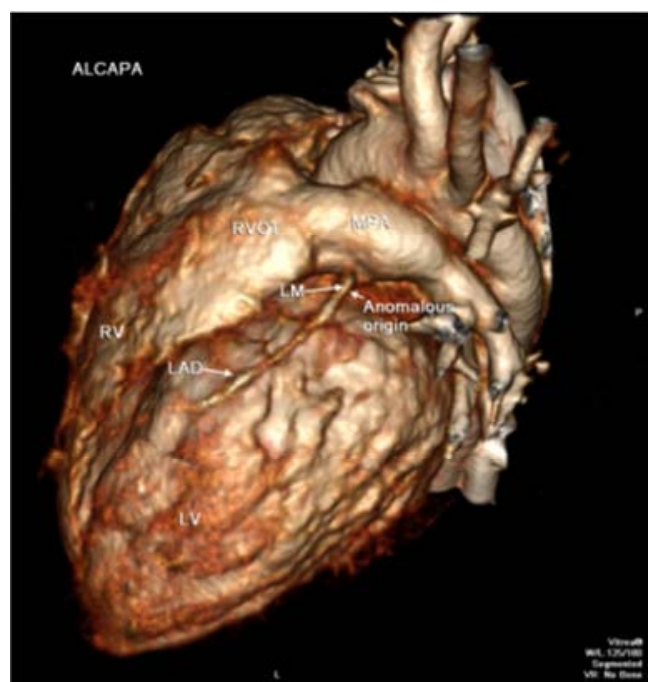

(B). 3D volume rendering image of heart and coronary arteries (Left lateral oblique view)

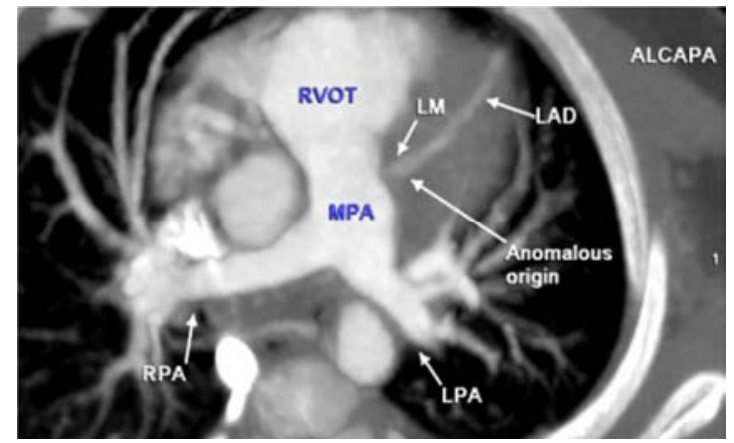

(C). Axial MIP image of LAD

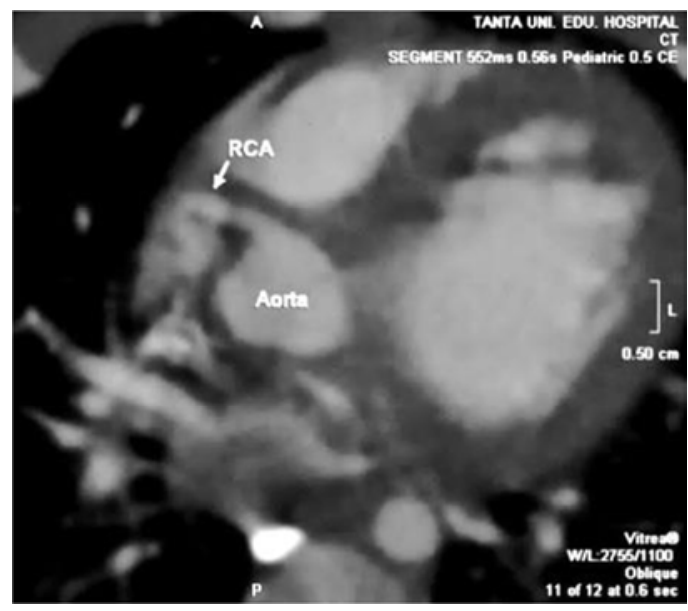

(D). Axial oblique MIP image of RCA origin

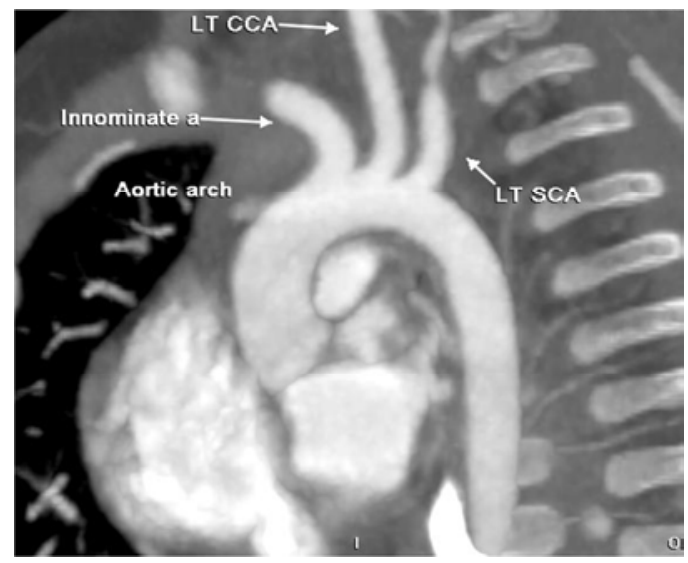

(E). Sagittal oblique MIP image of aorta and arch branches

Figure 3. A 2-month-old female patient with dilated left ventricle in echocardiography. MD-CTA reveals anomalies origin of LMCA from the main pulmonary artery which is mildly dilated $(A-C)$, mildly dilated left ventricle $(A, B)$, normal origin and caliber of RCC (D) and branching pattern of the aortic arch (E).

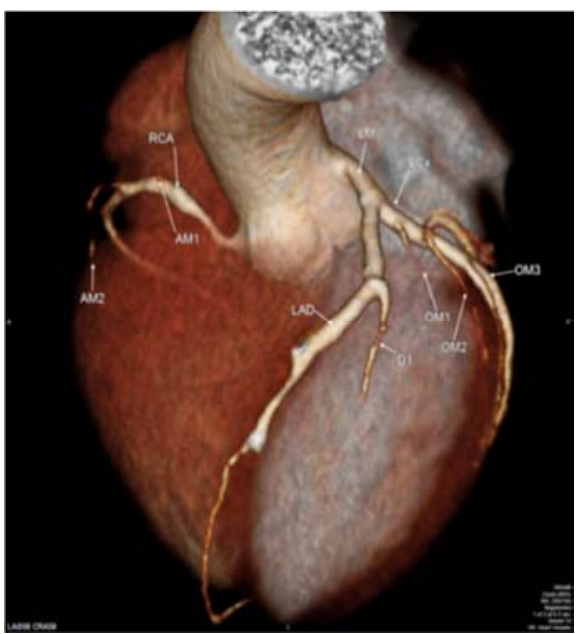

(A). 3D volume rendering image of heart and coronary arteries (Anterior oblique view) 


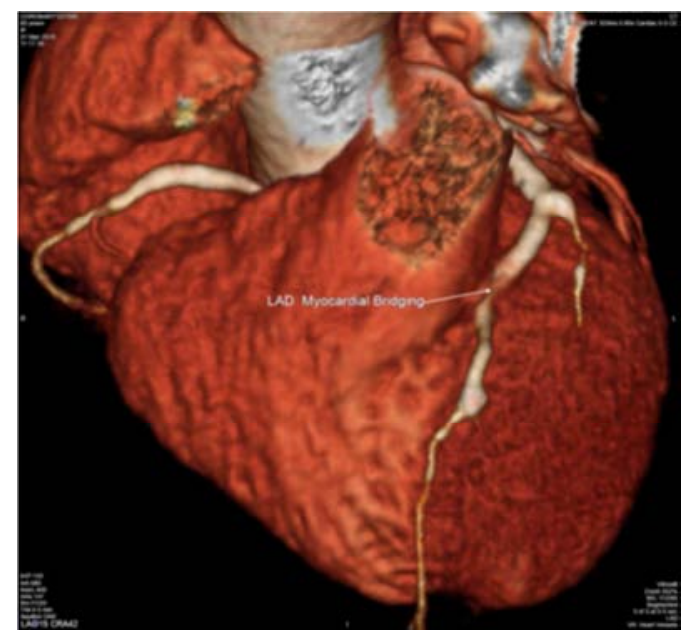

(B). 3D volume rendering image of heart and coronary arteries (Anterior view)

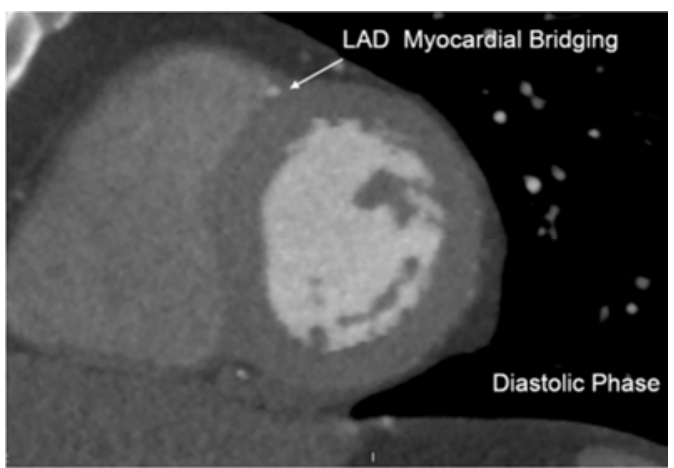

(C1) Curved planar reformatted image of LAD

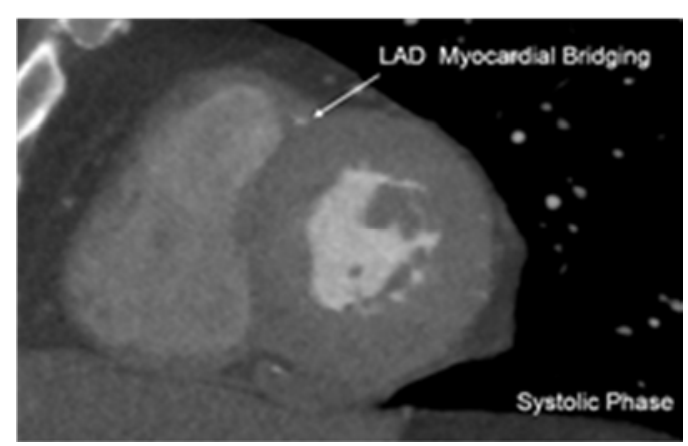

(C2) Two chamber view of LAD at systolic phase

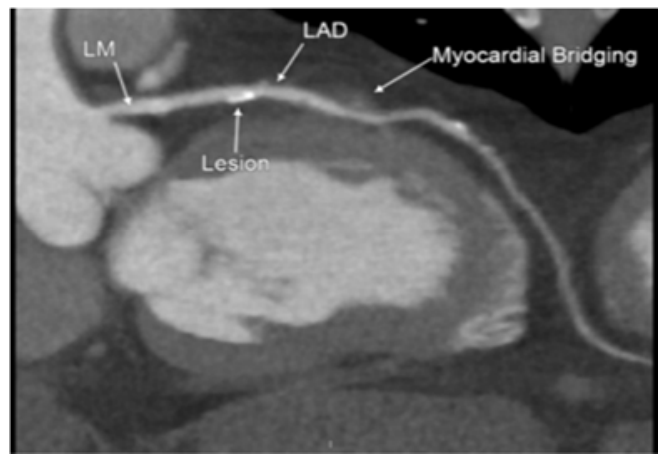

(C3) Two chamber view of LAD at diastolic phase

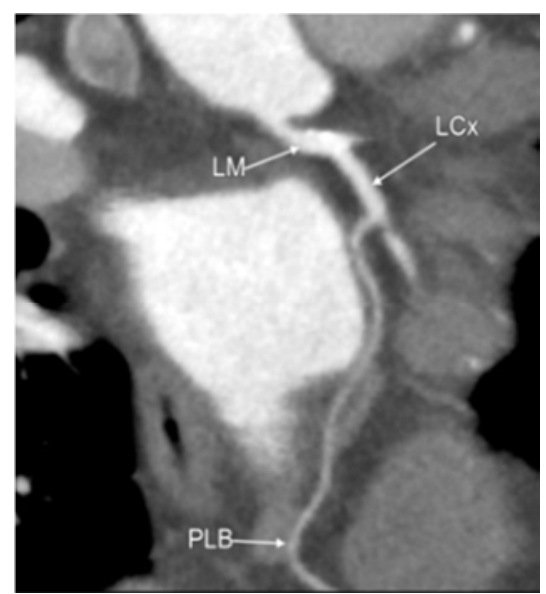

(D). Curved planar reformatted image of LCx

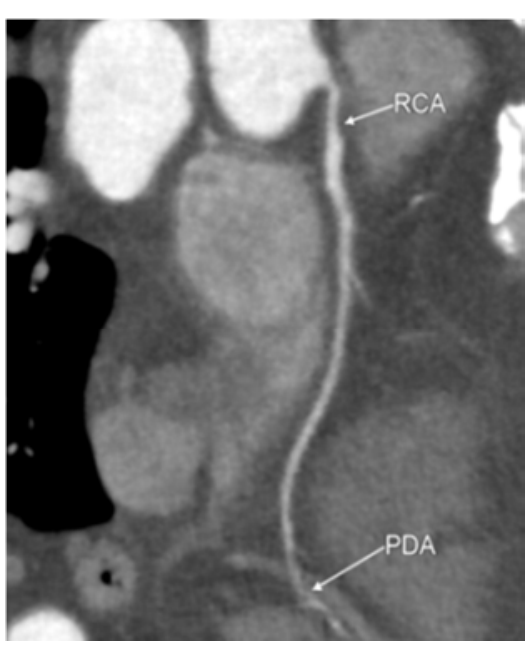

(E). Curved planar reformatted image of RCA

Figure 4. A -65-year old male patient presented with palpitation and atypical chest pain. MDCTA reveals LAD mid-segment deep myocardial bridging with moderate luminal compression in the systolic phase ((B-C3), normal origin and caliber of $L C x$ which supplies 3 patent $O M$ branches and ends posteriorly by supplying a patent $\operatorname{PLB}(A, D)$, normal origin and caliber of RCA that ends by supplying PDA $(A, E)$, co-dominant coronary circulation $(D, E)$ and atherosclerotic changes in the $L A D, D$ and PDA with total calcium score $=138$.

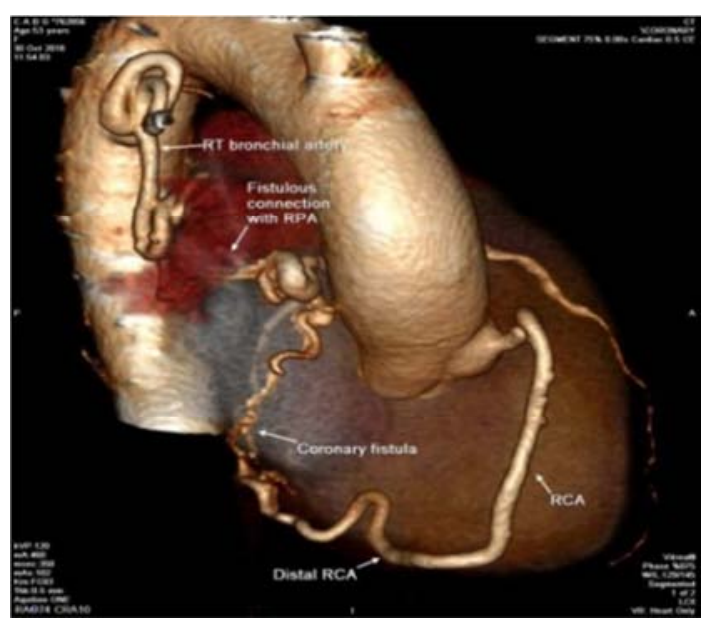

(A). volume rendering image of heart and coronary arteries (Posterior oblique view) 


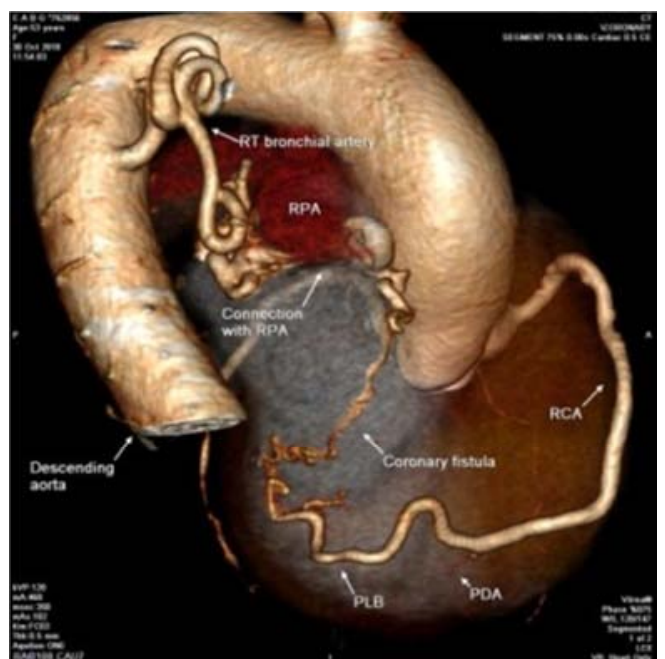

(B). volume rendering image of heart and coronary arteries (Posterior oblique view)

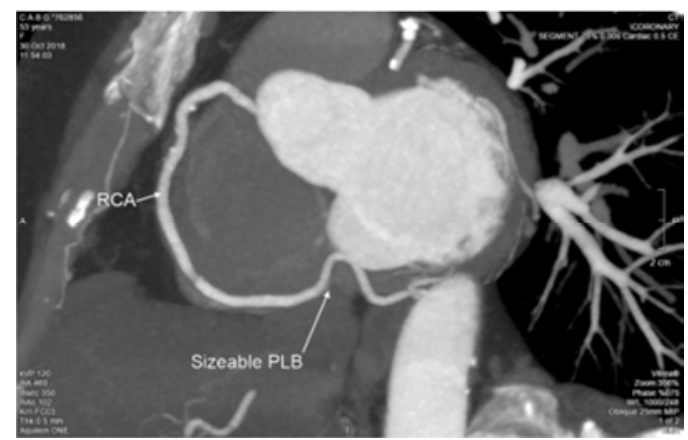

(C). Curved planar reformatted image of RCA and PLB

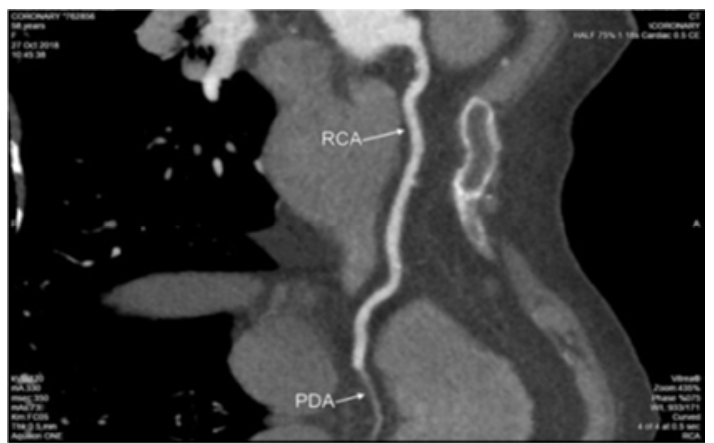

(D) Curved planar reformatted image of RCA and PDA

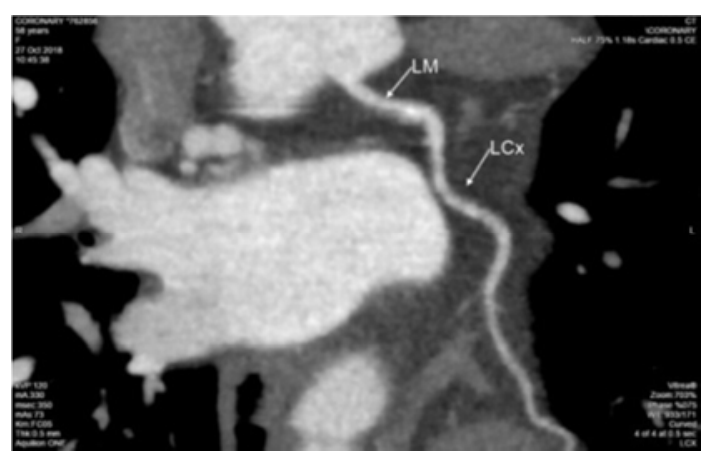

(E). Curved planar reformatted image of LAD

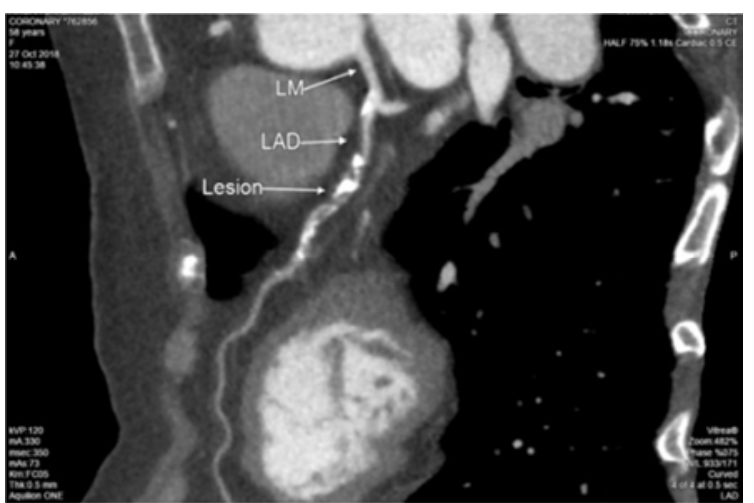

(F). Curved planar reformatted image of LCx

Figure 5. A 53-year-old female patient, presented clinically with dyspnea and atypical chest pain. MDCTA reveals a distal RCA fistula with right bronchial artery (RBA) and a short side fistulous tract with right pulmonary artery $(A, B)$, right dominant coronary circulation $(C, D)$, atherosclerotic changes in the LAD, RCA and LCX $(A-F)$ with total calcium score $=526$.

\section{Discussion}

The small dimensions and rapid movement of coronary arteries have made their evaluation with computed tomography (CT) challenging. However, because of the dramatic developments in the multi-detector computed tomography (MDCT) technology in the last decade, coronary CT angiography (CTA) has become an increasingly important non-invasive modality in the diagnosis of coronary artery diseases [7].

The most common age group involved in this study was $50-<60$ years. This is concordant with Rao et al [5] who stated the same most common age group. Female patients were more than male patients. Temel et al [8] also showed female predominance with female to male percentage was $52.2 \%$ to $47.8 \%$.

In the recent study, 320-slices CT machine was used, 217 coronary anomalies were detected among the 630 patients included in the study with their prevalence was $34.4 \%$. The current results were comparable to the results of Rao et al [5] that used 64-slices CT machine and the coronary anomalies prevalence was $29.3 \%$. Another study by Chaiyagool et al [7] showed almost double prevalence of coronary anomalies (61.6\%). On the other side, the present study results were higher than those of Tongut et al [4] with prevalence of $10 \%$.

Most of the studies detected prevalence of coronary anomalies were based on invasive coronary angiography (ICA); only few studies compared results of ICA and CT angiohraphy (CTA). The present study showed moderate agreement between ICA and CTA in course anomalies ( $\mathrm{K}$ value $=0.448$ and $\mathrm{P}$ value $<0.001)$ and good agreement in origin anomalies ( $\mathrm{K}$ value $=0.630$ and $\mathrm{P}$ value $<0.001)$. This was in line with Datta et al [9] who mentioned that the invasive coronary angiography demonstrates the exact site of origin of the anomalous vessel, but it was uncertain of the precise course while CT angiography provided accurate depiction of vessel origin and course.

Anomalies in coronary artery origin were detected in 
$10.9 \%$ of the studied cases with good agreement between CT coronary angiography and invasive coronary angiography $(\mathrm{K}$ value $=0.630)$, this percentage is comparable to Shehata et al [10], who found those anomalous in $7.4 \%$ of the studied cases with very poor agreement between CTA and ICA results ( $\mathrm{K}$ value $<0.2$ ). This difference in agreement may be attributed to missing the non selective aortic injection of contrast medium during the procedure of ICA and also the outcomes are operator dependent.

The present study included 7 patients with abnormal origin of right coronary artery from left coronary sinus out of 630 patients (1.1\%). Rao et al [5] reported those anomalies in $0.6 \%$ and Tongut et al, 2016 [4] reported them in $0.5 \%$ of the studied cases.

Two cases with high take off of right coronary artery above the sinotubular junction were detected with percentage of $0.3 \%$. This was nearly the same percentage as mentioned by Xiaorong et al [11] who showed percentage of $0.4 \%$. Meanwhile, Jonge et al [12] reported a percentage of $0.9 \%$.

Malignant course of the anomalous coronary artery located inbetween the aorta and the pulmonary arterial trunk with an increased risk for sudden death. The current study showed an incidence of this anomaly in $0.9 \%$ of the studied patients, this was in line with Alkhulaifi et al, 2017 [13] who reported nearly the same percentage $(0.8 \%)$. In the current study, one case was reported with RCA splittage into two arteries just after originating from its ostium in the right sinus of Valsalva $(0.1 \%)$ and this is similar to the results of a study of Kosar et al, 2009 [14].

Coronary artery ectasia was reported in $3.9 \%$ of the studied cases with a significant correlation between coronary CT angiography and invasive coronary angiography. This was approximately the same percentage and the statistic finding mentioned by Leschka et al [15], This anomaly was also most frequently found in the left anterior descending artery and less often in the right coronary artery, and circumflex artery. On the other hand, Leschka et al [15] found this anomaly most frequently in the right coronary artery and less often in the left anterior descending and circumflex artery.

Right coronary artery ectasia was detected in 8 patients. Leschka, et al [15] carried out their study on 13 patients and all of those cases were detected by both CTA and ICA with very good agreement $(\mathrm{K}$ value $=1.000)$. This was also in line with the present study.

Anomalies in RCA termination (RCA fistula) was rare. Only 1 case was detected in the current study. This case could be detected by both CTA and ICA with very good agreement $(\mathrm{K}$ value $=1.000)$. This came in agreement with Meave et al [16].

Six cases were reported with anomalous origin of left main coronary artery from right coronary sinus, representing a $0.9 \%$ of the involved patients. This nearly agreed with Rao et al [5].

Only one case was reported with anomalous origin of left main coronary artery from pulmonary artery (ALCAPA).
This was the same as reported by Jonge et al [12] in their study that was carried out on 230 patients and the anomaly was detected by both CTA and ICA with very good agreement $(\mathrm{K}$ value $=1.000)$. This was the same as noticed in the current study. Budoff et al [17] also reported 1 case with ALCAPA out of 6089 patients included in their study.

Left main coronary artery showed anomalies in its course represented by ectasia and aneurysm. Coronary artery aneurysm was detected in 2 patients with percentage of $0.3 \%$. This agreed with the reported percentage by Diaz-Zamudio et $a l$, [18] who also found a very good agreement between CTA and ICA $(\mathrm{K}$ value $=1.000)$.

As regard the coronary artery aneurysms, the present study showed very good agreement between CTA and ICA results $(\mathrm{K}=0.100)$ and this was in line with Duan et al [19] who also found a very good agreement with $(\mathrm{k}=0.870)$.

Absent left main coronary artery with separated origins of the left anterior descending (LAD) and left circumflex (LCX) arteries was found in $1.1 \%$ of the studied patients and this was a slightly higher incidence than mentioned by Prasad et al [20] and Mathai et al [21] who found this anomaly in $0.4 \% \& 0.6 \%$ of their patients respectively.

Myocardial bridging was considered the most common anomaly detected in the present study, and mostly affecting the mid segment of left anterior descending artery as seen in $14.3 \%$ of the patients with LAD myocardial bridging. Zeina et $a l$, [22] found this anomaly in $23.6 \%$ of the studied patients.

Left anterior descending coronary artery ectasia was detected in $9(1.4 \%)$ patients in the present study. Leschka, et al [15] reported LAD ectasia in 8 out of 677 (1.2\%) patients included in their study with very good agreement $(\mathrm{K}$ value $=$ 1.000). This was also in line with the recent study.

Anomalous origin of left circumflex (LCx) artery showed prevalence of $1.7 \%$ in the studied patients. This was similar to the findings of Jonge et al [12] in their study carried on 230 patients.

Left circumflex artery showed abnormal origin from right coronary sinus in $0.5 \%$ of the studied patients and $75 \%$ of them showed prepulmonic course and the remaining $25 \%$ showed trans-septal course, both are benign courses. This was in agreement with the findings of Prasad et al [20] in their study carried on 974 patients, but all of them showed retro-aortic courses.

The only reported course anomaly of left circumflex artery was ectasia which was reported in 4 out of 630 patients. This was the same as reported by Leschka, et al [15] in their study carried on 677 patients with very good agreement $(\mathrm{K}$ value= 1.000 and $\mathrm{P}$ value $<0.001)$. This also was in line with the recent findings.

The incidence of anomalies in coronary artery termination was $1.27 \%$. Pan et al [23] recorded an incidence of $0.33 \%$ and also recorded incidence of $0.02 \%$ for the right coronary artery fistula to right ventricle, while the recent study showed incidence of $0.2 \%$. These differences might be attributed to the difference in availability and the wide use of coronary CTA. 


\section{Limitations}

There are many limitations and challenges faced during this study. Visualization of the coronary artery was limited and the assessment of dominance was difficult in the studied paediatric patients because of their high heart rate and inability to stop breathing during examination, its use of ionizing radiation, all the subjects were referred from a single center, thus the study sample may not be representative for the whole population, small sample size of certain anomalies may cause statistical errors and few studies which compared results of ICA and CTA.

\section{Recommendations}

It is still recommended to control heart rate to a lower level to eliminate blurring artefacts, use of newer techniques of radiation dose reduction while retaining excellent spatial resolution, use of CTA for initial screening of congenital coronary anomalies of ectopic origin and in cases of detected anomalies origin of these vessels on ICA to detect its course and exclude malignant inter-arterial course.

\section{Conclusions}

(1) The prevalence of coronary anomalies is higher with multidetector coronary CT angiography (CTA) than invasive coronary angiography (ICA) even after exclusion of patients with myocardial bridging which is more frequently found with CTA. So the true prevalence of coronary anomalies in the general population may have been underestimated based on ICA.

(2) Electrocardiography (ECG) gated multidetector coronary computed tomographic angiography (CTA) with 3-D reconstruction provides excellent spatial and temporal resolution, allowing accurate anatomical assessment of coronary artery anomalies.

(3) Multidetector coronary CTA had added value of illustration of the intracardiac non coronary abnormalities, as well as extracardiac anatomical structures.

\section{References}

[1] Smettei OA, Sayed S and Abazid R. The prevalence of coronary artery anomalies in Qassim Province detected by cardiac computed tomography angiography. J Saudi Hear Assoc. 2017; 29 (2): 84-89.

[2] Yildiz A, Okcun B, Peker T, et al. Prevalence of coronary artery anomalies in 12,457 adult patients who underwent coronary angiography. Clin Cardiol. 2010; 33 (12): 60-64.

[3] Angelini P, Velasco JA and Flamm S. Coronary anomalies: incidence, pathophysiology, and clinical relevance. Circulation. 2002; 105 (20): 2449-2454.

[4] Tongut A, Özyedek Z, Çerezci İ, et al. Prevalence of congenital coronary artery anomalies as shown by multi- slice computed tomography coronary angiography: a singlecentre study from Turkey. J Int Med Res. 2016; 44 (6): 1492-1505.

[5] Rao A, Pimpalwar Y, Yadu N, et al. A study of coronary artery variants and anomalies observed at a tertiary care armed forces hospital using 64-slice MDCT. Indian Heart J. 2017; 69 (1): 81-86.

[6] Ernesto F, Inglese M, Infante T, et al. Anomalous of left main coronary artery detected by CT angiography. Surg Radiol Anat. 2016; 38 (8): 987-990.

[7] Chaiyagool K, Suwannanon R and Hongsakul K. Anatomic variants and anomalies of coronary arteries detected by computed tomography angiography in southern Thailand. Med J Malaysia. 2018; 73 (3): 131-136.

[8] Tuğba T, Enes C and Osman B. Prevalence and characteristics of coronary artery anomalies in children with congenital heart disease diagnosed with coronary angiography. Turk Kardiyol Dern Ars. 2017; 45 (6): 527-532.

[9] Datta J, White C, Gilkeson RC, et al. Anomalous coronary arteries in adults: depiction at multi-detector row CT angiography. Radiol. 2005; 235 (3): 812-818.

[10] Shehata S, Zaiton F, Warda M, et al. Value of MDCT as a noninvasive modality in evaluation of pediatric congenital cardiovascular anomalies. Egypt J Radiol Nucl Med. 2017; 48 (2): 467-478.

[11] Xiaorong L, Ou S, Ou SX, et al. Imaging diagnosis of congenital coronary artery anomalies by dual-source CT coronary angiography. poster present at, Eur Soc Radiol. 2014: 1-9.

[12] Jonge G, van Ooijen P, Piers L, et al. Visualization of anomalous coronary arteries on dual-source computed tomography. Eur Radiol. 2008; 18 (11): 2425-2432.

[13] Alkhulaifi A, Chooriyil N, Alkuwari M, et al. Coronary artery anomalies: unusually high incidence of anomalies with a malignant course in an Asian population. SAGE open Med. 2017; 5: 1-6.

[14] Koşar P, Ergun E, Öztürk C, et al. Anatomic variations and anomalies of the coronary arteries: 64-slice CT angiographic appearance. Diagnostic Interv Radiol. 2009; 15 (4): 275-283.

[15] Leschka S, Stolzmann P, Scheffel H, et al. Prevalence and morphology of coronary artery ectasia with dual-source CT coronary angiography. Eur Radiol. 2008; 18 (12): 2776-2784.

[16] Meave A, Melendez G, Ochoa JM, et al. Right coronary artery-to-right ventricle fistula in a pediatric patient evaluated by 64-detector-row computed tomographic coronary angiography. Texas Hear Inst J. 2009; 36 (5): 491-493.

[17] Budoff M, Ahmed V, Gul K, et al. Coronary anomalies by cardiac computed tomographic angiography. Clin Cardiol. 2006; 29 (11): 489-493.

[18] Díaz-Zamudio M, Bacilio-Pérez B, Herrera-Zarza B, et al. Coronary artery aneurysms and ectasia: role of coronary CT angiography. Radiographics. 2009; 29 (7): 1939-1954.

[19] Duan Y, Wang X, Cheng Z, et al. Application of prospective ECG-triggered dual-source CT coronary angiography for infants and children with coronary artery aneurysms due to Kawasaki disease. Br J Radiol. 2012; 85 (1020): e1190-e1197. 
[20] Prasad S and Vijayakumar D. Detection of coronary artery anomalies using 64 slice MDCT angiography. Int J Contemp Med Surg Radiol. 2017; 2 (3): 75-79.

[21] Mathai R, Fahmy D, Sadek H, et al. Congenital coronary artery anomalies in adult population detected using dual source ECG-gated CTA in a single institution. Folia Morphol. 2017; 76 (2): 208-218.
[22] Zeina A, Odeh M, Blinder J, et al. Myocardial bridge: evaluation on MDCT. Am J Roentgenol. 2007; 188 (4): 10691073.

[23] Pan Y, Chen G, Chen B, et al. Prevalence of coronary artery fistula in a single center of China. Chin Med J (Engl). 2018; 131 (12): 1492-1495. 